\title{
Change Detection Analysis Using Surveying and Geoinformatics Techniques
}

\author{
Onuigbo I.C. ${ }^{1}{ }^{*}$ and Jwat, J.Y. \\ ${ }^{1}$ Department of Surveying and Geoinformatics, Federal University of Technology, Minna, Nigeria \\ Corresponding Author: *anyi.onuigbo@ futminna.edu.ng
}

\begin{abstract}
The study was on change detection using Surveying and Geoinformatics techniques. For effective research study, Landsat satellite images and Quickbird imagery of Minna were acquired for three periods, 2000, 2005 and 2012. The research work demonstrated the possibility of using Surveying and Geoinformatics in capturing spatial-temporal data. The result of the research work shows a rapid growth in built-up land between 2000 and 2005, while the periods between 2005 and 2012 witnessed a reduction in this class. It was also observed that change by 2020 may likely follow the trend in 2005 - 2012 all things being equal. Built up area may increase to 11026.456 hectares, which represent $11 \%$ change. The study has shown clearly the extent to which MSS imagery and Landsat images together with extensive ground- truthing can provide information necessary for land use and land cover mapping. Attempt was made to capture as accurate as possible four land use and land cover classes as they change through time.
\end{abstract}

Keywords: Surveying, Geoinformatics, Analysis, Land use, Land cover

\subsection{Introduction}

Studies have shown that there are only few landscapes on the earth that are still in their natural state. Due to anthropogenic activities, the earth's surface is being significantly altered in some manner and man's presence on the earth and his use of land has had a profound effect upon the natural environment thus resulting into an observable pattern in the land use and land cover over time. In situations of rapid and often unrecorded land use change, observations of the earth from space provide objective information of human utilization of the landscape.

According to Meyer (1999), every parcel of land on the earth's surface is unique in the cover it possesses. Land use and land cover are distinct yet closely linked characteristics of the earth's surface. Globally, land cover today is altered principally by direct human use: by agriculture and livestock raising, forest harvesting and management and urban and suburban construction and development.

Conventional ground methods of land use mapping are labor intensive, time consuming and are done relatively infrequently. These maps soon become outdated with the passage of time, particularly in a rapid changing environment. In fact according to Olorunfemi (1983), monitoring changes and time series analysis is quite difficult with traditional method of surveying. In recent years, satellite remote sensing techniques have been developed, which have proved to be of immense value for preparing accurate land use and land cover maps and monitoring changes at regular intervals of time. To date, the most successful attempt in developing a general purpose classification scheme compatible with remote sensing data has been by Anderson et al. (1976) referred to as USGS classification scheme.

Ever since the launch of the first remote sensing satellite (Landsat-1) in 1972, land use and land cover studies were carried out on different scales for different users. For instance, waste land mapping of India was carried out on 1:1 million scales by NRSA using 1980 - 82 Landsat multi spectral scanner data. About $16.2 \%$ of waste lands were estimated based on the study. 
Change detection is the process of identifying differences in the state of an object or phenomenon by observing it at different times (Singh, 1989). Change detection is an important process in monitoring and managing natural resources and urban development because it provides quantitative analysis of the spatial distribution of the population of interest.

Macleod \& Congalton (1998) listed four aspects of change detection which are important when monitoring natural resources:

i. $\quad$ Detecting the changes that have occurred

ii. Identifying the nature of the change

iii. Measuring the area extent of the change

iv. Assessing the spatial pattern of the change

The basis of using remote sensing data for change detection is that changes in land cover result in changes in radiance values which can be remotely sensed. Techniques to perform change detection with satellite imagery have become numerous as a result of increasing versatility in manipulating digital data and increasing computer power. A wide variety of digital change detection techniques have been developed over the last two decades (Singh, 1989; Coppin \& Bauer, 1996).

It has been noted over time through series of studies that Landsat Thematic Mapper is adequate for general extensive synoptic coverage of large areas. As a result, this reduces the need for expensive and time consuming ground surveys conducted for validation of data.

An analysis of land use and land cover changes using the combination of MSS Landsat and land use map of Indonesia reveals that land use and land cover change were evaluated by using remote sensing to calculate the index of changes which was done by the superimposition of land use and land cover images of 1972, 1984 and land use maps of 1990 (Dimyati et al. 1995). This was done to analyze the pattern of change in the area, which was rather difficult with the traditional method of surveying as noted by Olorunfemi (1983), when he was using aerial photographic approach to monitor urban land use in developing countries with Ilorin in Nigeria as the case study.

Daniel et al.(2002), in their comparison of land use and land cover change detection methods, made use of 5 methods viz; traditional post - classification cross tabulation, cross correlation analysis, neural networks, knowledge - based expert systems, and image segmentation and object - oriented classification. A combination of direct T1 and T2 change detection as well as post classification analysis was employed. Nine land use and land cover classes were selected for analysis. They observed that there are merits to each of the five methods examined, and that, at the point of their research, no single approach can solve the land use change detection problem.

Coppin \& Bauer (1996) stated that detecting and characterizing change over time is the natural first step toward identifying the driver of the change and understanding the change mechanisms. Satellite remote sensing has long been used as a means of detecting and classifying changes in the condition of the land surface over time. Satellite sensors are well-suited to this task because they provide consistent and repeatable measurements at a spatial scale which is appropriate for capturing the effects of processes that cause change, including natural (e.g. fires, insect attacks) and anthropogenic (e.g. deforestation, urbanization, farming) disturbance. They also stated that the ability of any system to detect change depends on its capacity to account for variability at one scale, example, seasonal variations, which identifying change at another multi-year trends, only a limited number of time series change detection methods have been developed. The present status would not have been achieved without close interaction between various fields such as utility networks, cadastral mapping, topographic mapping, thematic cartography, surveying and photogrammetry, remote sensing, image processing, computer science, rural and urban planning, earth science, and geography. Image differencing is a more automated technique for detecting change. The method involves the subtraction of a recent image (time $)$ from an earlier image $\left(\right.$ time $\left._{2}\right)$, to detect radiance change between two dates resulting from a change in land cover.

Minna, the Niger State capital has witnessed remarkable expansion, growth and development such as buildings, road construction, deforestation and many other anthropogenic activities since its inception in 1976. This has therefore resulted in increased land consumption and a modification and alterations 
in the status of her land use land cover over time without any detailed and comprehensive attempt to evaluate this status as it changes over time with a view to detecting the land consumption rate and also make attempt to predict same and the possible changes that may occur in this status so that planners can have a basic tool for planning. Therefore, attempt was made in this study to determine the status of land use changes over a period of time between 2000 and 2012 with a view to detecting the land consumption rate and the changes that have taken place so as to predict possible changes that might take place in the next 20 years.

\subsection{Materials and Methods}

\subsection{Study Area}

Nyikamgbe a suburb of Minna, lies approximately on Latitude $9^{0} 39^{\prime} 40^{\prime \prime} \mathrm{N}$ to Latitude $9^{0} 35^{\prime} 14$ "' $\mathrm{E}$ and Longitude $6^{0} 31^{\prime} 26^{\prime \prime} \mathrm{N}$ to Longitude $6^{0} 31^{\prime} 26^{\prime \prime} \mathrm{E}$ (see Figure 1) on a geological base of undifferentiated basement complex of mainly gneiss. The land in Minna is essentially used for agricultural purpose. Within Minna, crops like maize, yam, melon, groundnuts are produced. Vegetable gardens are also maintained near some households. The largest percentage of the land is used for farming activities.

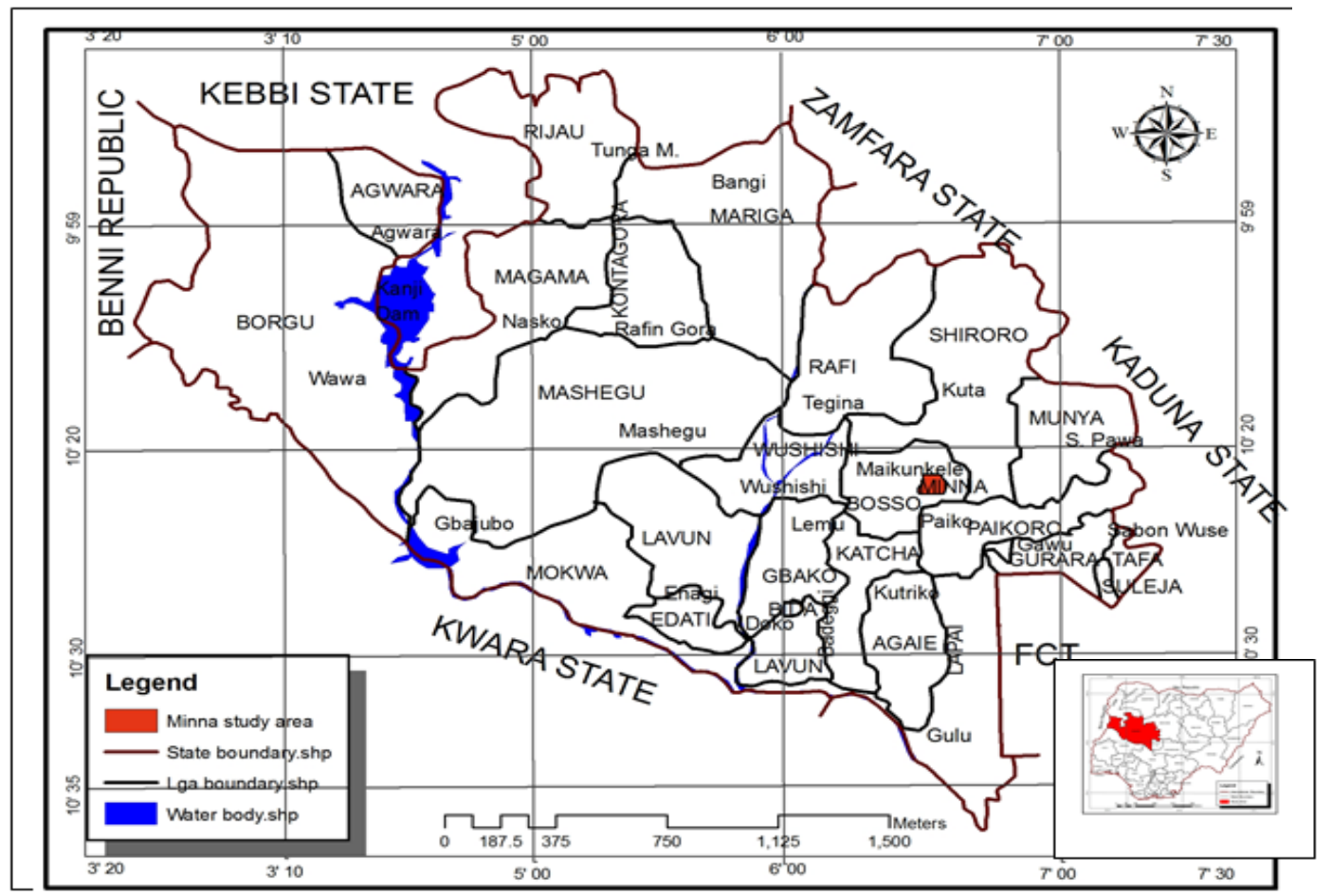

Figure1: Location map of Minna, Niger State in Nigeria

Source: Ministry of Land and Housing Minna, 2013

\subsection{Data Acquired and Sources}

For the study, Landsat satellite images and Quickbird imagery of Minna were acquired for three periods: 2000, 2005 and 2012, and analyzed according to the steps shown in Figure 2. It is also important to state that Minna and its environs which were carved out using the local government boundary map and Nigerian Administrative map was also obtained from Niger State Ministry of Town Planning. These were brought to Universal Transverse Marcator projection in Zone 31.

\subsection{Description of Data}

The sets of data used for the study area are Landsat and Quickbird Imagery covering the study area. Landsat Image data have potential applications for monitoring the conditions of the earth's land surface. The images can be used to map anthropogenic and natural changes on the earth over periods of several months to several years. Landsat Enhanced Thematic Mapper (ETM) was also obtained from Global Land Cover Facility on the internet. The Landsat ETM satellite has seven (7) bands like 
the Landsat TM but carries an additional panchromatic band (see Table 1). Landsat ETM has a spatial resolution of $30 \mathrm{~m}$ and the panchromatic band has a $15 \mathrm{~m}$ spatial resolution. The ETM has a temporal resolution of 16 days.

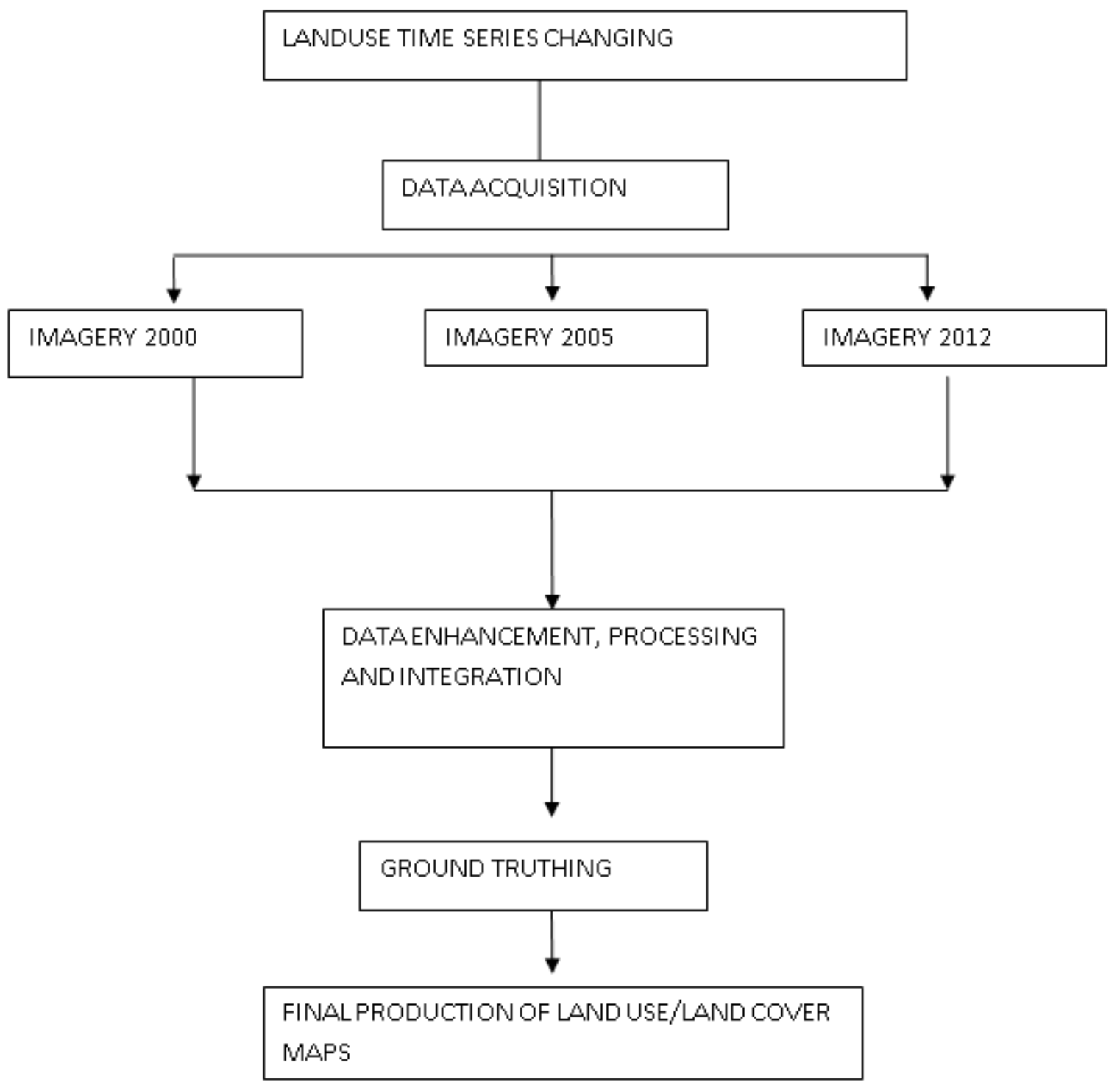

Figure 2: Flow model of analysis

Table 1: The wavebands of Landsat TM

\begin{tabular}{|l|l|l|}
\hline Bands & Wavelength $(\mu \mathrm{m})$ & Spectral location \\
\hline 1 & $0.45-0.52$ & Blue \\
\hline 2 & $0.52-0.60$ & Green \\
\hline 3 & $0.63-0.69$ & Red \\
\hline 4 & $0.76-0.90$ & NR \\
\hline 5 & $1.55-1.25$ & MR \\
\hline 6 & $10.4-12.5$ & Far \\
\hline 7 & $2.08-2.35$ & IR \\
\hline 8 & $0.52-0.90$ & Panchromatic \\
\hline
\end{tabular}

\subsection{Description of Landsat TM Imageries Utilized}

The Landsat TM imagery used is of scale 1: 2500. It sensed in seven bands. The spatial resolution is 30 meters (in the panchromatic mode). It has a swath width of $185 \mathrm{~km}$, meaning that each scene or image covers a distance of $185 \mathrm{~km}$.

\subsection{Geo-referencing}

One of the major tasks of image geometric operation is to rectify an image to a given map projection system. The process is called geocoding or georeferencing. The geo-referencing properties of both 
images are the same, while image thinning was applied to the 2000 imagery which has a low resolution using a factor of two to modify its properties and resolution to conform to the other two.

Image thinning was carried out through contract. Contract generalizes an image by reducing the number of rows and columns while simultaneously decreasing the cell resolution. Contraction may take place by pixel thinning or pixel aggregation with the contracting factors in $\mathrm{X}$ and $\mathrm{Y}$ being independently defined. With pixel thinning, every $\mathrm{n}^{\text {th }}$ pixel is kept while the remaining is thrown away.

\subsection{Software Used}

Basically, five softwares were used for this project via:

1. ArcView $3.2 \mathrm{a}$ - this was used for displaying and subsequent processing and enhancement of the image. It was also used for the carving out of Nyikamgbe from Minna imagery using both the admin and local government maps

2. ArcGIS - This was also used to compliment the display and processing of the data

3. Idrisi32 - This was used for the development of land use land cover classes and subsequently for change detection analysis of the study area.

4. Microsoft word - was used basically for the presentation of the research

5. SPSS was used for time series analysis

\subsection{Development of a Classification Scheme}

Based on the prior knowledge of the study area for over 12 years and a brief reconnaissance survey with additional information from previous research in the study area, a classification scheme was developed for the study area after Anderson, et al. (1976). The classification scheme developed gives a rather broad classification where the land use land cover was identified by a single digit (see Table 2).

Table 2: Land use land cover classification scheme

\begin{tabular}{|l|l|}
\hline Code & Land use land cover categories \\
\hline 1 & Farmland \\
\hline 2 & Built-up land \\
\hline 3 & Water bodies \\
\hline 4 & Wet vegetated land \\
\hline
\end{tabular}

\subsection{Analysis}

Three main methods of data analysis were adopted in this study:

1. Calculation of the Area in hectares and percentage of the resulting land use/land cover types for each study year and subsequently comparing the results.

2. Markov Chain and Cellular Automata Analysis for predicting change

3. Maximum Likelihood Classification

The three methods above were used for identifying change in the land use types. The comparison of the land use land cover statistics assisted in identifying the percentage change, trend and rate of change between 2000 and 2012. In achieving this, the first task was to develop a table showing the area in hectares and the percentage change for each year, measured against each land use land cover type. Percentage change to determine the trend of change can then be calculated by dividing observed change by sum of changes multiplied by 100 , as shown in the expression below:

Trend (Percentage change $)=\frac{\text { Observed change }}{\text { Sum of change }} \times 100$

In obtaining annual rate of change, the percentage change is divided by 100 and multiplied by the number of study year (12years). Going by the second method (Markov Chain Analysis and Cellular Automata Analysis), Markov Chain Analysis is a convenient tool for modeling land use change when changes and processes in the landscape are difficult to describe. A Markovian process is one in which 
the future state of a system can be modeled purely on the basis of the immediately preceding state. Markovian chain analysis will describe land use change from one period to another and use this as the basis to project future changes. This is achieved by developing a transition probability matrix of land use change from time one to time two, which shows the nature of change while still serving as the basis for projecting to a later time period. The transition probability may be accurate on a per category basis, but there is no knowledge of the spatial distribution of occurrences within each land use category. Hence, Cellular Automata (CA) was used to add spatial character to the model.

CA - Markov uses the output from the Markov Chain Analysis particularly Transition Area file to apply a contiguity filter to "grow out" land use from time two to a later time period. Overlay operations which is the last method of the three, identifies the actual location and magnitude of change although this was limited to the built-up land. Boolean logic was applied to the result through the reclass module of Idrisi32 which assisted in mapping out separately areas of change for which magnitude was later calculated for.

The Land consumption rate and absorption coefficient formula are as given below:

L.C.R $=\frac{\mathrm{A}}{\mathrm{P}}$

Where:

A Areal extent of the city in hectares

P Population

L.A.C $=\frac{A_{2}-A_{1}}{P_{2}-P_{1}}$

Where:

$A_{1}$ and $A_{2}$

$P_{l}$ and $P_{2}$

Areal extents (in hectares) for the early and later years

Population figure for the early and later years respectively (Yeates and Garner, 1976)

L.C.R Measure of compactness which indicates a progressive spatial expansion of a city.

L.A.C Measure of change in consumption of new urban land by each unit increase in urban population

\subsection{Results and Discussion}

\subsection{Land use land cover of Nyikamgbe Village}

\subsubsection{Landsat Imagery Analysis}

Landsat TM of the study area was used, the interpretation of land use category vector map covering the study area shown in Figure 3. 


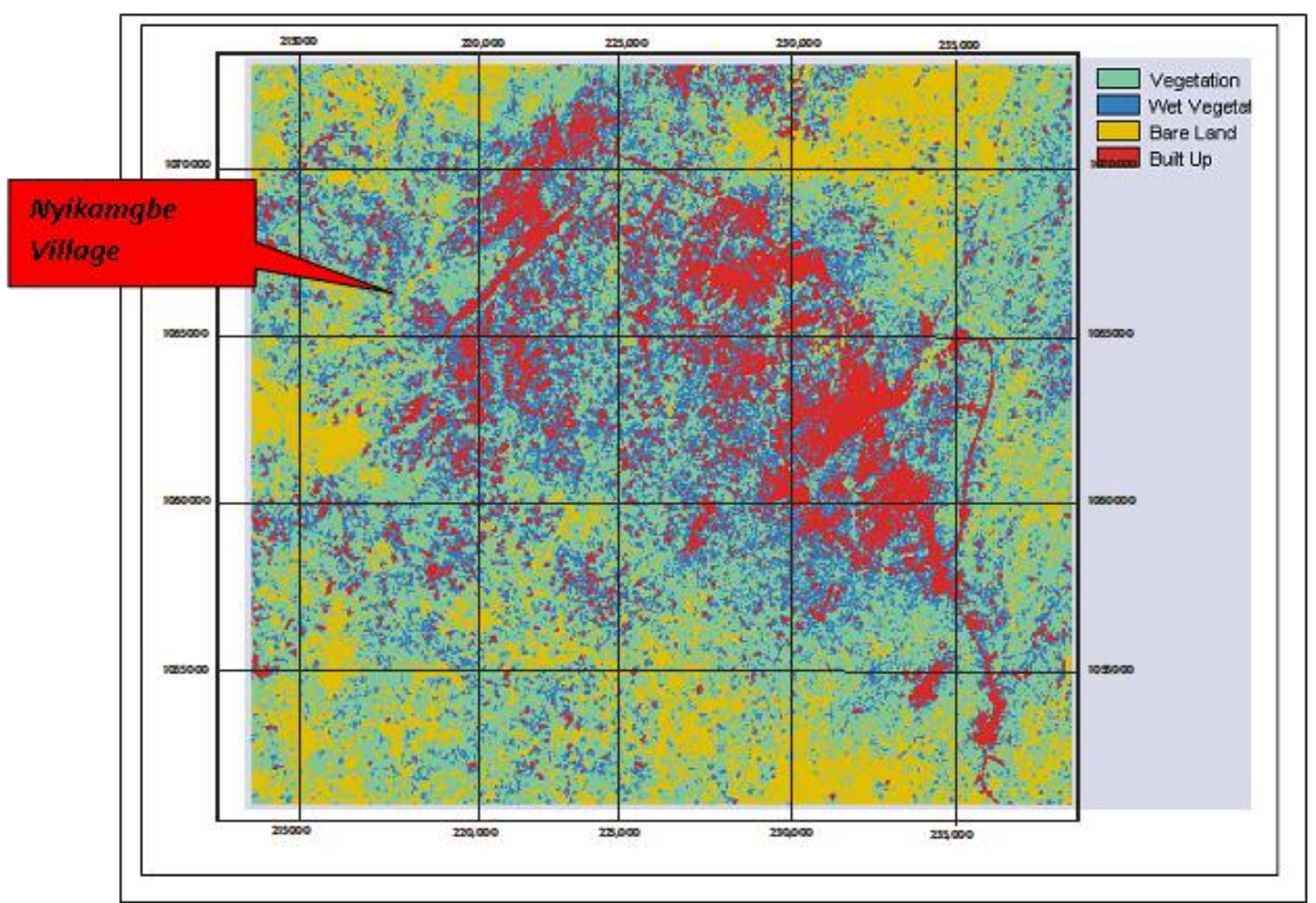

Figure 3: Landsat TM classification of Minna 2000

Ground truthing was carried out, using physical features as sample points. The interpreted image showed that vegetation covers about $87 \%$ of the area which made up the largest land use category. The built-up land comprises of mainly residential buildings which covers about $10 \%$ of the area of study.

\subsubsection{Quick bird Imagery analysis 2005}

The interpretation of imagery of 2005 for land use category covering the study area is shown in Figure 4. The classification map of 2005 shows the land use map of the study area. This period witnessed a great change in land use category. Most especially the built-up land, a striped residential land and commercial land was constructed which occupied 217 ha. However, the ground truthing showed that commercial services were present in the clustered residential area ranging from, shops, and mini supermarkets to shopping complexes. Also, present here are mosques, churches and schools.

\subsection{Estimating Future Changes}

The transition probability matrix records the probability that each land cover category will change to the other category. This matrix is produced by the multiplication of each column in the transition probability matrix by the number of cells of corresponding land use in the later image.

For the 4 by 4 matrix table presented below (see Table 3), the rows represent the older land cover categories and the column represents the newer categories. Although this matrix can be used as a direct input for specification of the prior probabilities in maximum likelihood classification of the remotely sensed imagery, it was however used in predicting land use land cover of 2015. 


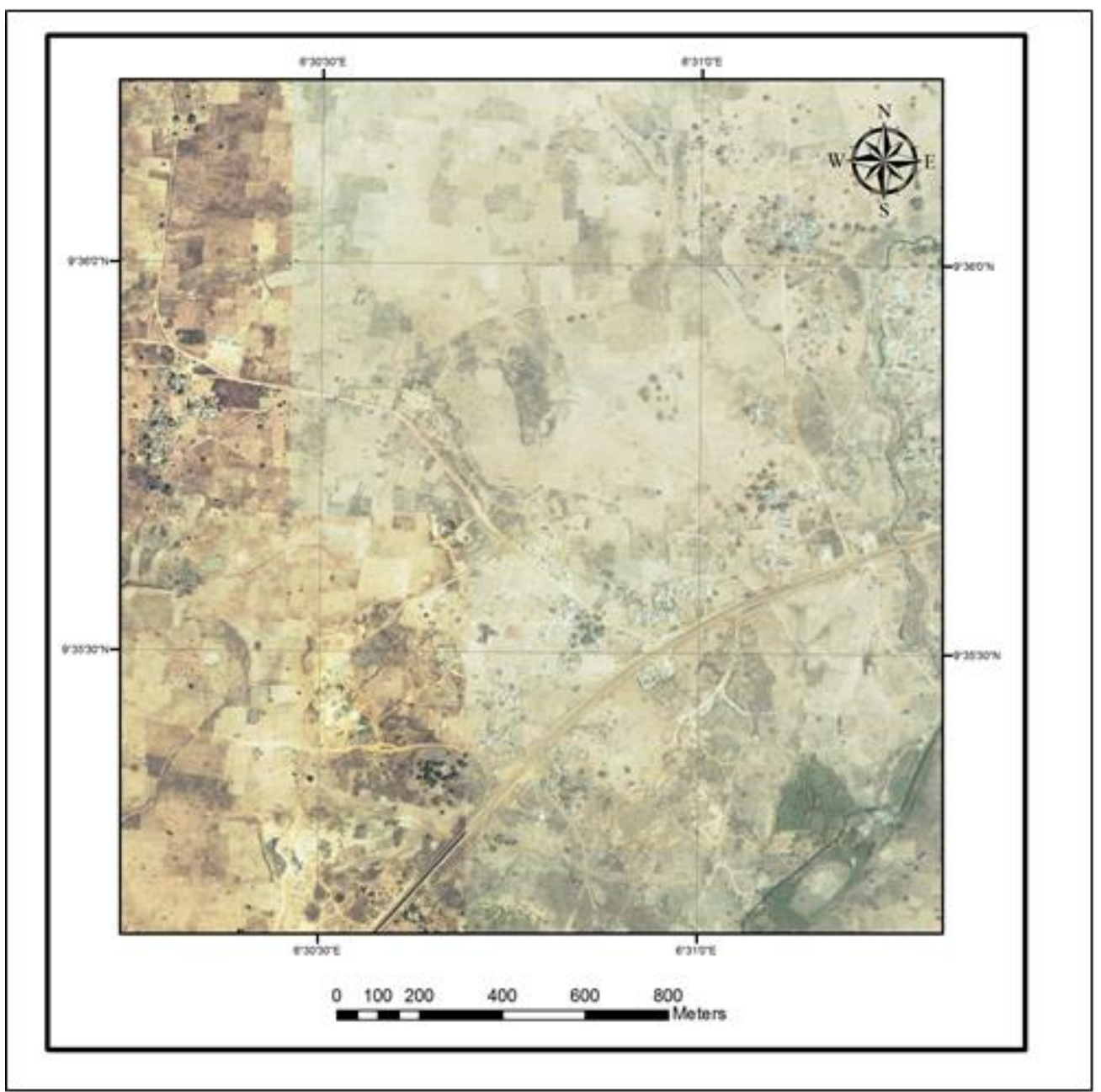

Figure 4: QuickBird imagery showing land use of study area in 2005

Table 3: Transitional Probability table derived from the land use land cover map of 2005 and 2012

\begin{tabular}{|l|l|l|l|l|}
\hline Classes & Wet Vegetated Land & Farm Land & Intensive Built-up Land & Water Body \\
\hline Wet Vegetated land & 0.1495 & 0.5553 & 0.0885 & 0.0097 \\
\hline Farm land & 0.1385 & 0.5132 & 0.1735 & 0.0057 \\
\hline Intensive Built-up land & 0.0471 & 0.3902 & 0.5029 & 0.0090 \\
\hline Water body & 0.1682 & 0.4378 & 0.0633 & 0.0133 \\
\hline
\end{tabular}

Row categories represent land use land cover classes in 2005 whilst column categories represent 2015 classes. As seen from the table, farm land has a 0.1495 probability of remaining farm land and a 0.5553 of changing to wet vegetated land in 2015. This therefore shows an undesirable change (reduction), with a probability of change which is much higher than stability. Farm land during this period will likely maintain its position as the highest class with a 0.5132 probability of remaining farm land in 2015.Built-up land also has a probability as high as 0.5029 to remain as built-up land in 2015 which signifies stability. On the other hand, the 0.4050 probability of change from wet vegetated land to farm land shows that there might likely be a high level of instability within this period. Water body which is the last class has a 0.0133 probability of remaining as water body and a 0.4378 probability of changing to wet vegetated land; which may not however be a true projection of this class except there is an occurrence of drought in the region.

Table 4 shows the statistics of land use land cover projection for 2015. Comparing the percentage representations of this table and that of Table 5, there exist similarities in the observed distribution particularly in 2005. 
Table 4: Land Use Land Cover Projection for 2015

\begin{tabular}{|l|l|l|l|l|}
\hline $\begin{array}{l}\text { Land use land } \\
\text { cover classes }\end{array}$ & $\begin{array}{l}\text { Wet vegetated } \\
\text { land }\end{array}$ & Farm land & $\begin{array}{l}\text { Intensive built-up } \\
\text { land }\end{array}$ & Water body \\
\hline Area in Hectares & 16583.5458 & 47432.4759 & 11026.456 & 20397.871 \\
\hline Area in Percentage & 17 & 50 & 11 & 21 \\
\hline
\end{tabular}

Table 5: Land Cover/Land Use in Percentage

\begin{tabular}{|l|l|}
\hline Landuse & Percentage \\
\hline Intensive Built-up & $39.6 \%$ \\
\hline Farmland & $32.2 \%$ \\
\hline Wet vegetated land & $6.2 \%$ \\
\hline Water body & $12 \%$ \\
\hline
\end{tabular}

This may tend to suggest no change in the classes between 2005 and 2015, but a careful look at the area in hectares between these two tables shows a change though meager. Thus in Table 4, farm land still maintains the highest position in the class, followed by water body, wet vegetated land and finally by intensive built-up land.

\subsection{Statistical Analysis}

Statistical analysis was carried out on the data obtained from the study. The results shown in Table 6, shows that more developments in terms of residential, commercial, road network (physical structures) have taken place in 2012 compared to 2005.

Table 6: Results of Statistical Analysis

\begin{tabular}{|l|l|l|l|l|l|l|l|}
\hline Land Use & $\begin{array}{l}\text { Quickbird } \\
\text { Imagery }\end{array}$ & $\begin{array}{l}\text { Landsat } \\
\text { Imagery }\end{array}$ & $\mathrm{X}=\mathrm{x}-\overline{\mathrm{x}}$ & $\mathrm{Y}=\mathrm{y}-\overline{\mathrm{y}}$ & $\mathrm{X}^{2}$ & $\mathrm{Y}^{2}$ & $\mathrm{XY}$ \\
\hline Residential & 176.61 & 488.80 & 53.77 & 365.96 & 2891.21 & 133926.72 & 19677.67 \\
\hline Commercial & 11.18 & 36.58 & -111.66 & -86.26 & 12467.96 & 7440.79 & 9631.79 \\
\hline Industrial & 4.06 & 12.60 & -118.78 & -110.24 & 14108.69 & 12152.86 & 13094.31 \\
\hline $\begin{array}{l}\text { Public/semi- } \\
\text { public }\end{array}$ & 48.83 & 40.83 & -74.01 & -82.01 & 5477.48 & 6725.64 & 6069.56 \\
\hline $\begin{array}{l}\text { Open } \\
\text { space/green } \\
\text { area }\end{array}$ & 64.99 & 58.57 & -57.85 & -64.27 & 3430.44 & 4130.63 & 3718.02 \\
\hline $\begin{array}{l}\text { Road } \\
\text { network }\end{array}$ & 42.30 & 57.95 & -80.54 & -64.89 & 6486.69 & 4210.71 & 5226.24 \\
\hline Agriculture & 511.90 & 164.52 & 389.06 & 41.68 & 151367.68 & 1737.22 & 16216.02 \\
\hline Total & 859.85 & 859.85 & & & $\sum \mathrm{X}^{2}=196230.15$ & $\sum \mathrm{Y}^{2}=170324.57$ & $\sum \mathrm{XY}=73633.61$ \\
\hline
\end{tabular}

Product moment correlation coefficient (r):

$$
\begin{aligned}
& \text { Mean }=\frac{\sum \mathrm{x}}{\mathrm{N}}=\frac{859.85}{7}=122.84 \\
& \mathrm{r}=\frac{\sum \mathrm{XY}-\sum \mathrm{X} \sum \mathrm{Y}}{\sqrt{\left[\mathrm{n} \sum \mathrm{X}^{2}-\left(\sum \mathrm{X}\right)^{2}\right]\left[\mathrm{n} \sum \mathrm{Y}^{2}-\left(\sum \mathrm{Y}\right)^{2}\right]}} \\
& \mathrm{r}=\frac{7(73633.61)-(859.85)(859.85)}{\sqrt{\left[7(196230.15)-(859.85)^{2}\right]\left[7(170324.57)-(859.85)^{2}\right]}} \\
& \mathrm{r}=-0.42
\end{aligned}
$$

Bivariat regression (b):

$$
\begin{aligned}
& \mathrm{b}=\frac{\sum \mathrm{XY}-\sum \mathrm{X} \sum \mathrm{Y}}{\sum \mathrm{X}^{2}-\left(\sum \mathrm{X}\right)^{2}} \\
& \mathrm{~b}=\frac{7(73633.61)-(859.85)(859.85)}{7(196230.15)-(859.85)^{2}} \\
& \mathrm{~b}=-0.35
\end{aligned}
$$


Therefore:

$\mathrm{a}=\mathrm{y}-\mathrm{bx}$

$\mathrm{a}=122.84-(-0.35 \times 122.84)$

$\mathrm{a}=165.83$

Therefore, the least squares regression line $\mathrm{Y}=\mathrm{a}+\mathrm{bX}$ becomes Equation (7) shown below. This equation shows the rate of change of land cover from 2005 to 2012.

$\mathrm{Y}=165.83-0.35 \mathrm{X}$

Where:

$X \quad$ size (area) of land in 2005 as obtained from Quick Bird image, 2005

$Y \quad$ prediction of change

\subsection{Conclusion and Recommendation}

This research work demonstrated the ability of Remote Sensing, GIS and Time Series analysis in capturing spatial-temporal data. Attempt was made to capture as accurate as possible five land use land cover classes as they change through time. Except for the inability to accurately map out water body in 2000 due to the aforementioned limitation, the five classes were distinctly produced for each study year but with more emphasis on built-up land as it is a combination of anthropogenic activities that make up this class; and indeed, it is one that affects the other classes.

However, the result of the work shows a rapid growth in built-up land between 2000 and 2005 while the periods between 2005 and 2012 witnessed a reduction in this class. It was also observed that change by 2020 may likely follow the trend in 2005-2012 all things being equal. Built up may increase to 11026.456 which represent $11 \%$ of changes.

The study has shown clearly the extent to which MSS imagery and Landsat images interaction techniques with extensive ground truthing can be of help in providing biophysical information necessary for landuse landcover mapping. Landuse maps could provide baseline information for resource planner and manager and would also assess the changes and effect created by development projects.

Based on the findings, the following recommendations are made:

1. Frequent acquisition of remote sensing data, particularly SPOT and Landsat imageries for multi-temporal study of Minna and environs is recommended with a view to monitoring changes.

2. People should be given positive orientation on their attitude towards land management in relation to the environment.

\section{References}

Anderson et al. (1976). A Land Use and Land Cover Classification System for Use with Remote Sensor Data. Geological Survey Professional Paper No. 964, U.S. Government Printing Office, Washington, D.C. p. 28.

Coppin, P. \& Bauer, M. (1996). Digital Change Detection in Forest Ecosystems with Remote Sensing Imagery. Remote Sensing Reviews, 13, 207-234.

Daniel et al. (2002). A comparison of Landuse and Landcover Change Detection Methods. In: Procs ASPRS-ACSM Annual Conference and FIG XXII Congress p. 2.

Dimyati et al. (1995). An Analysis of Land Use/Land Cover Change Using the Combination of MSS Landsat and Land Use Map- A case study of Yogyakarta, Indonesia. International Journal of Remote Sensing, 17(5), $931-944$. 
Macleod \& Congalton (1998). A Quantitative Comparison of Change Detection Algorithms for Monitoring Eelgrass from Remotely Sensed Data. Photogrammetric Engineering \& Remote Sensing, 64(3), $207-216$.

Meyer, W.B. (1999). Past and Present Land-use and Land-cover in the U.S.A. Consequences, 24-33.

Olorunfemi, J.F. (1983). Monitoring Urban Land - Use in Developed Countries - An aerial photographic approach. Environmental Int.9, 27 - 32.

Singh, A. (1989). Digital Change Detection Techniques Using Remotely Sensed Data. International Journal of Remote Sensing, 10(6), 989-1003.

Yeates, M and Garner, B. (1976). The North American City. Harper and Row Pub. N. Y. 